\title{
When an intercultural business negotiation fails: Comparing the emotions and behavioural tendencies of individualistic and collectivistic negotiators
}

\section{Introduction}

Negotiation is an important tool for managing interdependence and the intensification of global business activity has increased the need for negotiating across borders. An impressive body of literature has highlighted the challenges faced by negotiators in intercultural negotiations (e.g. Adair and Brett 2005; Brett and Okumura 1998; Bulow and Kumar 2011; Gelfand et al. 2013; Hofstede et al. 2012; Kumar 1999a; Lee et al. 2006; Ready and Tessema 2009). This literature has underscored the importance of differences in influence strategies, patterns of information sharing, and conflicting negotiating styles in shaping negotiating processes and outcomes. Yet, there are few empirical studies that examine the nature of emotional reactions among negotiators in a cross-cultural negotiating process or how such emotional reactions may shape the negotiating dynamics (Adam and Shirako 2013; Cropanzano et al. 2012).

The study of emotion in intercultural negotiations is still in its infancy. The neglect of emotions in the study of intercultural negotiations is somewhat surprising inasmuch as cultural distance creates uncertainty about how one's counterpart might behave in negotiation and/or how one should deal with him/her. The distance may also lead to expectancy violations that further enhance the uncertainty that exists among the participants (Mandler 1975; Mendes et al. 2007). Expectancy violations may occur either because of under-adaptation or even because of over-adaptation to the cultural norms of one's counter-negotiator (Adair et al. 2009). The resulting uncertainty can be detrimental to effective interaction because it may generate negative emotions such as 
anxiety and induce the participants to behave in ways that may enhance rather than reduce the cultural distance between them (Duronto et al. 2005; Gudykunst 1988, 2005; Hullett and Witte 2001; Samochowiec and Florack 2010). Although anxiety has been the main emotion that has been investigated by Gudykunst's anxiety/management theory, other emotions may be equally crucial in shaping intercultural adaptation that is an area that remains inadequately explored. Assessing the role of emotions is critical because they shape behaviour and influence judgments that individuals form of one other (van Kleef et al. 2004).

Overcoming these potential emotional biases necessitate greater effort, more persistence, and a more positive and proactive orientation all of which may be unfavourably impacted upon by negative emotions (Seo et al. 2004). Kopelman and Rosette (2008) have also highlighted the importance of the display of emotions on negotiation outcomes. Their study involving East Asian and Israeli negotiators showed that in the East Asian cultural context, where the demonstration of respect is important, negotiators who displayed negative emotions were less likely to be successful in their negotiations.

Moreover, a major feature of emotions is that they are associated with action tendencies (Frijda 1986; Lazarus 1991) and this has implications for the strategies that the negotiators choose to follow. For example, anger may lead to a retaliatory spiral (Allred 1999; Allred et al. 1997), while tension may lead to a withdrawal or an agreement (Kumar 1999a). Anger and tension are both negative emotions with the latter being closely linked to fear (Shaver et al. 1987).

In one of the few empirical studies to date, Lee et al. (2006) demonstrated that in an intercultural negotiation setting involving Chinese and American executive MBA students both groups of participants experienced tension but its behavioural 
consequences were different for the two groups. The Chinese reacted to the emergence of tension by trying to reach an agreement but the level of trust for their American counterparts declined. Trust is considered to be of critical importance in intercultural negotiations (e.g. Gunia et al. 2011) and the study by Lee et al. (2006) buttresses the argument made by Jones and George (1998) that emotions have an impact on trust judgments. For the Americans, by contrast, the emergence of tension had a negative impact on their ability to reach an agreement. This may be related to the differential perspective-taking ability of collectivists and individualists (Wu and Keysar 2007) that, in turn, carries implications for emotional volatility of negotiators.

Third, negotiators embedded in different cultures approach negotiations differently (e.g. Adair et al. 2001; Adair et al. 2009; Brett 2000, Kumar 1999a). Negotiators from collectivistic cultures have as their uppermost priority the establishment of a relationship as opposed to their individualistic counterparts (e.g. Kumar 1999b). Collectivistic negotiators exchange information indirectly whereas their individualistic counterparts exchange information directly (e.g. Adair et al. 2001). Different approaches to negotiation may interfere with the ability of the negotiators to accomplish their goals and in the process give rise to negative emotions.

Fourth, the negative emotions experienced by negotiators from different cultures are likely to be different (Kumar 2004), although to date this remains an untested theoretical prediction. It has been maintained that members of individualistic cultures are likely to experience dejection-related emotions whereas members of collectivistic cultures are likely to experience agitation-related emotions (Kumar 2004). Dejectionrelated emotions represent the absence of a positive outcome whereas agitation-related emotions represent the presence of a negative outcome (Higgins 1987). 
As our review suggests, emotions can have a powerful impact on the processes and outcomes of intercultural negotiations. The purpose of this study is to demonstrate the linkage between cultural variation (individualistic and collectivistic cultures) and the types of discrete emotions that are most prevalent in an unsuccessful intercultural business negotiation. In a failed intercultural negotiation, negative emotions are the likely consequence and we wish to explore if the type of negative emotion that gets activated is a function of culture. Thus, this study wishes to contribute to cross-cultural business negotiation research by enhancing our understanding of the emotional dynamics of intercultural negotiating processes. We focus on negative emotions because how individuals deal with them have significant consequences for the success or the failure of a negotiation. A negative emotion such as anger may invite an aggressive response and in doing so set up a vicious spiral which drags the parties further apart rather than bringing them closer (Pruitt et al. 2003). Positive emotions are addressed less extensively in this research.

More specifically, the contribution of the paper is three fold. First, we provide the first pieces of empirical evidence showing that qualitatively different emotions (dejection vs. agitation) may be experienced after a failed business negotiation by collectivists and individualists. Second, we reveal the existence of the relationship between perspective-taking ability and emotional volatility in the context of failed business negotiation involving collectivists and individualists. Third, we propose and test the idea that discrete negative emotions resulting from a failed business negotiation lead to different behavioural tendencies in collectivistic and individualistic cultures.

We begin by discussing the concepts of emotions, culture and their interlinkages. This leads to the elaboration of three research hypotheses which are then tested using a scenario analysis of an intercultural negotiation involving Indian and 
Finnish study participants. The paper concludes with a discussion highlighting the theoretical implications, avenues for future research, and the limitations of the study.

\section{Theoretical framework for the study}

The conceptual elaboration consists of brief reviews of affect and culture. Their integrative consideration culminates into the development of research hypotheses.

\section{The role of affect}

Barsade and Gibson (2007) conceive of affect as an overarching term that comprises of discrete emotions, moods, and feeling traits (see also Barry et al. 2004). Discrete emotions have a specific cause, are accompanied by physiological reactions, and are associated with action tendencies (Bagozzi et al. 1999; Frijda 1986; Yzerbyt et al. 2003). Thus, the discrete emotion of anger is associated with the action tendency of aggression while the discrete emotion of fear is associated with the action tendency to escape. Emotions are short-lived phenomena that can be characterized in terms of their frequency, intensity, and duration (Kumar 1997). Moods, by contrast, represent general feelings of pleasantness or unpleasantness and are not associated with any specific cause. Dispositional affect, on the other hand, is a personality trait that characterizes an individual's tendency to experience positive or negative moods and emotions (Watson and Clark 1984).

This study seeks to focus on discrete emotions for two key reasons. First, the intercultural negotiating process is a goal-driven activity and the negotiators may either experience success or failure in achieving their goals. A major theme in the emotion literature is that positive emotions arise when actors are able to attain their goals and the process has been a smooth one and negative emotions are likely to emerge when the 
actors are unable to achieve their goals and the process has been a difficult one (Lazarus 1991). As Lazarus (1991, p. 111) notes: "Emotional outcomes are based on whether or not our goals and expectations have been realized and in what ways". The specificities of the negotiation process and the associated outcomes are likely to contribute to the emergence of discrete emotions in the negotiating process. As different discrete emotions have different behavioural implications (Frijda 1986; Lazarus 1991), it is important to consider not just the valence of an emotion (positive or negative) but more importantly the specific type of positive or negative emotion.

Second, given that emotions are short-lived high intensity states, and that they have specific action tendencies associated with them, it is pertinent and relevant to assess the impact of discrete emotions. For example, anger can lead the negotiators to behave aggressively which may further escalate the conflict whereas negative emotions such as tension or anxiety may induce the negotiators to withdraw from the negotiation which is also detrimental to a positive outcome (Gibson and Callister 2010; Kumar 1997, 1999a). As noted earlier, a distinction has also been drawn between two classes of negative emotions, namely dejection- vs. agitation-related (Higgins, 1987). Dejectionrelated emotions comprise being angry at other, disappointed, dissatisfied, frustrated, hopeless, irritated, regretful, and sad. They are symptomatic of the fact that the desired outcomes have not been attained. Agitation-related emotions, by contrast, represent the presence of a negative outcome. They are comprised of being angry at self, anxious, apprehensive, ashamed, fearful, pressured, self-blaming and tense. These emotions link the negative outcome to a presumed failure on one's part and hence the presence of emotions such as self-blaming or ashamed.

Even though certain basic emotional experiences can be regarded as universal (Ekman 1992), socio-cultural context greatly impacts on the kind of emotions 
experienced by individuals and how they respond to them (Markus and Kitayama 1991). Thus, it is important to assess the impact of culture on the nature of the emotional experience of individuals situated in different socio-cultural contexts. We now turn to an exploration of the cultural construct and its potential influence on the kind of emotions that individuals situated in different contexts might experience.

\section{National culture}

National culture characterizes the social ethos of a group and may be defined as the "... collective programming of the mind" (Hofstede 2001, p. 1). The individualismcollectivism dimension has by far received the greatest attention in cross-cultural research (e.g. Bond 1994; Brewer and Chen 2007) and it has a long history in social science theorizing (e.g. Brewer and Chen 2007; Markus and Kitayama 1991; Shweder and Bourne 1984).

Individualists differ from collectivists along a number of dimensions (Chen et al. 1998). Individualists emphasize their personal goals whereas the collectivists give precedence to group goals over their individual goals. Individualists are low context communicators whereas collectivists are high context communicators. Individualists are goal- or task-oriented whereas collectivists are more concerned with relationships and harmony management. The individualists also view themselves as “... independent and possessing a unique pattern of traits that distinguish them from other people" (Goncalo and Staw 2006, p. 97) whereas the collectivists view themselves as being in an interdependent relationship with members of their group.

Culture influences the perception of a negotiating outcome or a situation by the cognitive schemas that negotiators bring to bear on an event (Kumar 1999a). A schema is a cognitive structure that defines the key attributes about a particular object and the 
interrelationships that might exist between the different attributes (Fiske and Taylor 1991). Cultural values furnish group members with a schema or a knowledge structure that helps them to make sense of a particular situation (Brett and Okumura 1998; Adair et al. 2009). Schemas represent a generalized pattern of sense making that allows the participants to understand the behaviour of their partners and to respond appropriately, and they differ from mental models in that the latter are context dependent (Liu et al. 2012). A negotiation script is a particular type of schema which specifies the sequence by which a given activity is to be completed (Schank and Abelson 1977). Scripts represent a temporal ordering in which certain activities take precedence over others. A negotiation script, for example, might outline the different steps that need to be undertaken sequentially to conclude the negotiation. It might also define the processes by which any negotiation impasses are resolved. In essence, the different cognitive scripts highlight the distinctive approaches to negotiation in different cultures.

In Confucian-based cultures such as Japan relationship building is an essential first step in the negotiating process, whereas in the individualistic North American and European cultures relationship building in the sense that it is practiced in East Asia is a rarity (Kumar 1999b). Conflicting negotiation scripts will disrupt the negotiating process as each negotiator violates the other's expectations. Interruptions will be commonplace as each actor is thwarted from proceeding with the negotiation in the manner that they are used to. Interruptions give rise to emotions (Mandler 1975) and it is to be noted that different emotions are likely to be differentially salient in these cultures. In relational cultures, emotions that are conducive to fostering relationships or emotions that detract from such relationships may be most salient whereas in goaldriven cultures, emotions associated with the successful or unsuccessful completion of an activity may be the most salient (Markus and Kitayama 1991). 
Culture and emotions in intercultural negotiations: Developing research hypotheses

Although emotions are an inextricable part of human existence, there are differences in the emotional states that are likely to be prevalent in different cultures (e.g. Kitayama et al. 2006; Kumar 2004; Markus and Kitayama 1991). The behavioural incompatibility that emerges in the intercultural negotiating process gives rise to negative emotions that may impede this goal-relevant process (Kumar 1999a). A distinction has been drawn between achievement and prevention goals (e.g. Bosmans and Baumgartner 2005; Higgins 1987).

The achievement goals relate to an individual's ability to either be or not to be successful in any goal pursuit. When individuals succeed in their achievement goals, they experience elation or cheerfulness, but when they fail they experience dejection (Bosmans and Baumgartner 2005). Prevention goals relate to the individual's ability to avoid failure. When individuals are able to avoid failure, they are likely to be calm or quiescent, but when they are unable to avoid failure, they experience agitation (Bosmans and Baumgartner 2005; Higgins 1987). The distinction between dejection and agitation is subtle but, nevertheless, highly consequential for how negotiators may behave, since different emotions are associated with different behavioural tendencies in different cultures (Kumar 1999a).

The key distinction between the achievement and prevention goals revolves around the fact that the same situation can be construed in different ways by different negotiators. Consider, for example, the fact that a negotiation has been unsuccessful. Those negotiators, who have focused on achievement goals, will feel disappointed or sad (cf. dejection) due to absence of a positive outcome. By contrast, those negotiators, who have focused on prevention goals, will feel tension or fear (cf. agitation), as they 
have been unable to prevent a negative outcome (i.e. the failure of negotiation) from occurring.

The key assumption in this research is that while negotiators in both individualistic and collectivistic cultures may potentially experience both sets of emotions (dejection vs. agitation), it is the relative dominance of one over the other that is likely to be culturally dependent. In particular, it is predicted that in individualistic cultures dejection-related emotions are likely to be more prevalent whereas in collectivistic cultures agitation-related emotions are likely to be more dominant. As discussed earlier, individualistic cultures are goal-oriented (achievement goals) and the absence or the inability to attain a positive outcome may therefore give rise to dejectionrelated emotions (Higgins 1987; Kumar 1999a).

In turn, collectivistic cultures are harmony-oriented cultures where potential threats to harmony are taken seriously. When a pre-existing harmony is brought into question or when harmony fails to get established, it represents the presence of a negative outcome in a collectivistic culture. Failure in harmony attainment may cause loss of face which is an outcome that needs to be studiously avoided (prevention goals) in collectivistic cultures both because it violates deeply held local norms and also because face-repair is often a prolonged process (Earley 1997; Kim and Nam 1998). Although face is important in all cultures, its importance is greater in collectivistic as opposed to individualistic cultures (Kim and Nam 1998). A loss of face in a collectivistic culture leads to a critical evaluation of the entire self which may generate a sense of “.... Being small, and of being worthless" (Kim and Nam 1998, p. 527). When face is threatened collectivists are likely to experience agitation-related emotions such as fear because the potential consequences are so severe. A failure to successfully conclude a negotiation implies an absence of harmony and this may be a face- 
threatening outcome. Avoiding loss of face is therefore an important prevention-related goal and, not surprisingly agitation-related emotions in the nature of fear, tension, or anxiety may be dominant here (Kumar 1999a). This leads to the following hypothesis.

\section{Hypothesis 1: In an unsuccessful intercultural business negotiation, (a) negotiators from individualistic cultures predominantly experience dejection-related emotions, while (b) negotiators from collectivistic cultures predominantly experience agitation-related emotions.}

This study also explores the role of perspective-taking in shaping the emotional responses that may emerge among negotiators. Theorists have talked about the importance of perspective-taking, that is, “... the intrapsychic processes of imagining another's thoughts, motives, or feelings from that person's point of view." (Williams 2007, p. 601). In this study, perspective-taking is defined as a cognitive process in which individuals adopt others' viewpoints in an attempt to understand their preferences, values and needs (Parker and Axtell 2001).

In a negotiation context, this adoption of others' viewpoints mainly concerns various kinds of interests. Both negotiating parties are likely to be driven by a desire to protect and maximize their personal interests (e.g. getting a promotion or saving face) as well as the interests of the organizations they work for (e.g. market growth or wellbeing of employees). According to the motivated information processing theory, individuals' active motives shape cognitive processing by making them to selectively notice, encode and retain information that is consistent with their desires (Kunda 1990; Nickerson 1998).

As defined above, perspective-taking refers to cognitive ability to consider and appreciate others' viewpoints. In the present research context, this implies that those 
negotiators with higher levels of perspective-taking ability (boosting the interestcongruent selective information processing) understand more clearly (in comparison to negotiators with lower levels of perspective-taking ability) that maximizing their own self-interest requires being sensitive to the interests of the counter-negotiator as well. This realization facilitates concession-making and tolerance towards the ambitions of other party (cf. Galinsky et al. 2008). Perspective-takers understand the available competitive stakes and aggressive strategies, and yet promote mutual co-operation for joint gain. This blending of realistic cognitive assessment with what appears to be a prosocial motivation explains why perspective-taking has broad social benefits. (Gilin et al. 2013)

Thus, perspective-taking can be advantageous in intercultural negotiations. First, by being able to assess, how one's counterpart views the situation, the negotiator may be better able to understand the other's interests, needs, and goals, and in so doing to better calibrate one's negotiation strategy. Galinsky et al. (2008) suggest that perspective-taking allows negotiators to override their passions and to find the right balance between competition and co-operation and this enhances the possibility of a successful agreement. Thus, in a negotiation that is about to get derailed, staying emotionally calm or less volatile should be easier and more productive for negotiators with a high level of perspective-taking ability than for the negotiators with a lower perspective-taking ability. As a matter of fact, prior research suggests that perspectivetaking promotes cooperative behaviour (Parker and Axtell 2001) and leads to positive negotiation outcomes (Galinsky et al. 2008) as well as to a greater tendency to forgive the behaviour of the other actor (McCullough et al. 1997).

Second, scholars maintain that collectivists, as opposed to the individualists, are better in their perspective-taking ability (e.g. Wu and Keysar 2007). Collectivists 
prioritise group accomplishments over their own and this makes them to adapt to the needs or the demands of other people. Being more sensitive to other people implies that collectivists understand better the perspective and interests of an out-group member, while for individualists this ability is weaker leading them to emphasize with the perspective of an in-group member (cf. Usunier 2003).

If collectivists have a greater perspective-taking ability, relative to their individualistic counterparts, their experiences and particularly their emotional responses are not solely influenced by their own sets of interests. In other words, the collectivists, as opposed to the individualists, are likely to be both more understanding and tolerant of their counterpart's behaviour. This greater understanding should lessen the amplification of their emotional responses when looking at the situation from the standpoint of their counterparts. This leads to the second hypothesis.

Hypothesis 2: In an unsuccessful intercultural business negotiation, negotiators from collectivistic cultures demonstrate lower emotional volatility relative to their individualistic counterparts.

As discussed earlier, different sets of emotions are associated with different types of action tendencies (Frijda 1986; Lazarus 1991). It is hypothesized that dejectionrelated emotions should lead individualistic negotiators to show an approach tendency (Kumar 1999a). The key rationale is that dejection-related emotions signify the inability of the negotiators to fulfil their achievement-related goals (absence of a positive outcome) that gives rise to frustration and/or anger. These dejection-related emotions often lead to aggressive behaviour as individualists redouble their efforts to obtain the desired outcome; this should show as a heightened approach tendency (Berkowitz 1989; Kumar 1999a). 
On the other hand, in collectivistic cultures face-maintenance plays a singularly important role and disruption of harmony (failing in attaining their relational goals) is to be avoided. Agitation-related emotions can be expected to lead collectivistic negotiators to show an approach tendency. This is because tangible outcomes are of less importance for negotiators with a collectivistic mind set than for those negotiators who possess an individualistic mind set (Kim and Nam 1998). Scholars also suggest that collectivists are more inclined to use strategies such as obliging, that is, accommodating to the other party's concerns (Oetzel and Ting-Toomey 2003; Ting-Toomey et al. 2000; TingToomey and Kurogi 1998). In effect, agitation-related emotions are likely to facilitate the obliging attempts at re-establishment of harmony (i.e. face and relationship repair).

In other words, agitation-related emotions can promote an approach tendency among collectivistic negotiators, since approach tendency may be regarded as the mechanism by which these negotiators seek to repair their relationships and, in doing so, defuse conflicts among the parties. In sum, our third hypothesis states that different types of negative emotions can lead to the same behavioural tendency among negotiators with in different cultural mind sets.

Hypothesis 3: In an unsuccessful intercultural business negotiation, a) negotiators who experience higher level of dejection-related emotions and possess a more individualistic mind set demonstrate a higher level of approach tendency, and so do also b) negotiators who experience higher level of agitation-related emotions and possess a more collectivistic mind set. 


\section{Methodology}

The hypotheses were tested using a scenario analysis with business students from Finland (in the list of 64 countries, Finland belongs to the highest tercile in terms of Hofstede's individualism-score, de Mooij 2004) and India (Indian culture has been consistently characterized as collectivistic, Sinha and Kanungo 1997; Gupta and Panda 2003). A scenario analysis involves the construction of a hypothetical situation that approximates the real situation. For the purposes of the present study, a negotiation scenario involving an intercultural negotiating encounter between the individualists and the collectivists was used (see Appendices A and B).

Students were asked to read a negotiation transcript of a failed negotiation outcome between an American (individualistic culture; primarily oriented towards the achievement goal) and a Japanese (collectivistic culture; primarily oriented towards the prevention goal) company. Each Indian and Finnish student was randomly assigned the role of either an American (David) or a Japanese (Ishikawa) negotiator and asked to read the negotiation transcript from that perspective. In the case of David, the students were instructed to imagine themselves as the Vice President of Marketing at Alpha Corporation, an American company, who is involved in licensing negotiations with a Japanese company that is interested in licensing their technology. According to the transcript, David's team has come to Japan to conclude the negotiations with the Japanese company. In the case of Ishikawa, in turn, the students were instructed to imagine themselves as the General Manager of a Japanese pharmaceutical, who is involved in licensing negotiations with an American company that is interested in licensing their technology for the new drug. The transcript further read that the American team has come to Japan to conclude the negotiations with Ishikawa. Having gone through the negotiation transcript assigned to them, the students responded to a 
series of questions related to emotions and behavioural intentions. Study participants were also asked to indicate how well they identified with the role that was assigned to them. Finally, they responded to the individualism-collectivism scale and provided their demographic information.

The scenario that we used involved a negotiation between the Americans and the Japanese. Although the Indians and the Finnish students may lack an awareness of concrete specificities of American and Japanese negotiating patterns, it is important to point out that the scenario depicted a typical pattern of negotiating between individuals embedded in a collectivistic culture and individuals embedded in an individualistic culture. It was assumed that Finnish and Indian business students have an implicit understanding about individualism and collectivism and images of American and Japanese in their minds enabling them to identify themselves with the roles of both David and Ishikawa. This assumption was proved correct. The Finns could identify equally well with the roles of David and Ishikawa ("How well did you identify with the role of David/Ishikawa?", scale ranging from $0=$ "not at all" to $4=$ "extremely well): $\mathrm{M}_{\text {David, FIN }}=1.79$ vs. $\mathrm{M}_{\text {Ishikawa, FIN }}=1.55, \mathrm{SD}_{\text {David, FIN }}=0.89$ vs. $\mathrm{SD}_{\text {Ishikawa, FIN }}=0.81$, $\mathrm{t}(105)=1.45, \mathrm{p}>.05$. This same held true for the Indians as well: $\mathrm{M}_{\text {David, IND }}=2.37 \mathrm{vs}$. $\mathrm{M}_{\text {Ishikawa, IND }}=2.18, \mathrm{SD}_{\text {David, IND }}=0.90$ vs. $\mathrm{SD}_{\text {Ishikawa, IND }}=0.84, \mathrm{t}(104)=1.141, \mathrm{p}>.05$.

\section{Use of scenario analysis}

Most negotiation studies involve the use of a negotiation or a bargaining game (e.g. Brett and Okumura 1998; Kopelman et al. 2006; Lee et al. 2006). However, some scholars (e.g. Barry et al. 2004) have questioned whether emotions can be experienced in a laboratory setting, given its artificiality and the lack of personal stakes in the situation at hand. 
At the same time, it has been pointed out that scenario-based studies are particularly germane for studying sensitive issues, such as emotions (Wilks 2004), and they are not uncommon in the field of negotiation research (see e.g. van Kleef et al. 2006). The argument has also been made that such studies can lessen personal biases because individuals are asked to respond to the situation on the basis of a character in the scenario rather than on the basis of their own viewpoint (Hughes and Huby 2002). It has also been suggested that scenarios make it easier to attain cross-cultural equivalence as a standardized stimuli is presented to the participants (Leung and Bond 1984).

The negotiation scenario that was utilized for the purposes of this study describes a failed negotiation between an American and a Japanese company. The transcript is based on an extensive review of the literature of how the Japanese and the Americans negotiate. The transcript (as well as the accompanying questionnaire) was translated into Finnish for the Finnish sample and then back-translated into English to ensure translation accuracy (detection of errors and ambiguities). As English is widely spoken and well understood in India, it was not deemed necessary to effect such a translation into Hindi for the Indian sample.

\section{Study participants}

A total of 106 Finnish and 114 Indian Master's level business students participated in the study. The students were enrolled in a Master's program at their respective institutions. The mean age of the Finnish students was $25.3(\mathrm{SD}=6.67)$ whereas the mean age of the Indian students was $23.4(\mathrm{SD}=2.88)$. The Finnish sample consisted of 40 men and 64 women while the Indian sample consisted of 77 men and 24 women. Finnish and Indian students were chosen as exemplars of individualism and collectivism for two fundamental reasons. First, as already discussed, Finland was regarded to 
represent a culture in which individualism predominates over collectivism whereas in India the case was believed to be the opposite (these assumptions were confirmed, see the Results-section). Second, there has been an imbalance in prior research concerning cross-cultural negotiation literature in that most studies have drawn from East Asian and North American samples.

\section{Measures}

Individualism-collectivism. The INDCOL-scale was used (Singelis et al. 1995) to measure individualism and collectivism. The scale is popular and has been wellvalidated (Triandis and Gelfand 1998), but for a recent critique see Roberts et al. (2006). Some scholars have more broadly challenged the validity of self-construal scales, while others have suggested that this criticism may be overblown (Kim and Raja 2003; Levine et al. 2003). The INDCOL-scale is a 32-item measure which rests on the assumption that individualism (16 items; e.g. "Competition is the law of nature." and "When I succeed, it is usually because of my abilities.") and collectivism (16 items; e.g. "I usually sacrifice my self-interest for the benefit of my group." and "I feel good when I co-operate with others.") are different constructs and not different poles of a single dimension ( $\mathrm{Li}$ and Aksoy 2007). The response options ranged from 1 = "totally disagree" to $9=$ "totally agree".

Emotions. A 30-item battery of emotions (Ulijn et al. 2005), assessing the frequency with which they were experienced as study participants read the scenario, was utilized. This 30-item list consists of positive emotions, dejection-related emotions, agitationrelated emotions, other negative emotions and a neutral emotion (see Table 1). Dejection-related emotions - being angry at other, disappointed, dissatisfied, frustrated, 
hopeless, irritated, regretful and sad - are indicative of a situation characterized by the absence of a positive outcome. Agitation-related emotions - angry at self, anxious, apprehensive, ashamed, fearful, pressured, self-blaming and tense - on the other hand, characterize the presence of a negative outcome. The participants were asked to select the option that best describes how often they felt (when playing the role of David or Ishikawa) that way (each of the listed emotions) during the negotiation. A five-point scale ranging from $0=$ "never" to $4=$ "almost always" was used.

'Insert Table 1 here'

The item-total correlation tests were conducted for checking the homogeneity of the individualism/collectivism- and emotion-scales. Using the threshold level of 0.20 (Everitt 2002, p. 196) for ensuring appropriate levels of unidimensionality and purifying the scales, a number of items were discarded from the final constructs. Cronbach's alpha values for the scales were as follows: individualism $\left(\alpha_{\text {Finland }}=0.768 ; \alpha_{\text {India }}=\right.$ $0.687)$, collectivism $\left(\alpha_{\text {Finland }}=0.690 ; \alpha_{\text {India }}=0.679\right)$, agitation $\left(\alpha_{\text {Finland }}=0.693 ; \alpha_{\text {India }}=\right.$ $0.650)$ and dejection $\left(\alpha_{\text {Finland }}=0.872 ; \alpha_{\text {India }}=0.796\right)$. Thus, all the alpha coefficients are above or only slightly below Nunnally's (1978) frequently used threshold of 0.70 of good measurement reliability and well above the 0.60 threshold of acceptable reliability (Moss et al. 1998).

Approach-avoidance tendency. Study participants' desire or willingness to engage in any future interaction with their negotiating counterparts was assessed by asking them: "If you were in the situation of David (Ishikawa) how desirable would it be for you to (a) get out of the negotiation as soon as possible?; and (b) to accidentally meet David (Ishikawa) at a party in the evening?" These questions tap into negotiators' state level desire to either exit the negotiation situation or maintain contact with their negotiating 
counterpart over time. They were derived from the work of Mehrabian and Russell (1974) who identified four dimensions of approach-avoidance: (i) desire to stay in the situation; (ii) desire to explore the situation; (iii) desire to work in the situation; and (iv) desire to affiliate in the situation. While question (a) directly concerns negotiations, question (b) has clear implications for them. That is, if the negotiators consider it desirable to meet their counterparts accidentally in the evening of the day they negotiated, it is indicative of their wish to reinitiate interactions with them. That, in turn, may provide the basis for restarting the negotiations. The approach and avoidance tendency were measured using a five-point scale ranging from $0=$ "not at all" to $4=$ "tremendously".

Perspective-taking ability. To avoid respondent fatigue (vignette and research questions without perspective-taking measures yielded a 12-page questionnaire), a single-item measure of perspective-taking ability was collected from the study participants. The Indian and Finnish students were asked to indicate how well they could identify themselves with the role assigned to them (David or Ishikawa), using a 5-point scale ranging from $0=$ "not at all" to $4=$ "tremendously well". Additional rationale for this measurement is that the pre-existing scales concerning perspective-taking (e.g. Davis 1983) tackle individual differences in the general ability to view various issues from an alternative standpoint, thus being ill-fitted for the study adopting the role-playing and third-person technique.

\section{Results}

Prior to testing the research hypotheses, it is necessary to determine whether individualism or collectivism is more dominant in the sample countries. The analysis of 
the individualism/collectivism proportions (via an independent samples t-test) shows that they are significantly different $(t=3.21, p<0.01)$. In line with our assumptions, in India $(\mathrm{M}=0.95, \mathrm{SD}=0.18)$ collectivism is emphasized more than in Finland $(\mathrm{M}=1.05$, $\mathrm{SD}=0.26$ ), where individualism is the dominant mind set. To facilitate the interpretation of the results, the inspection of Tables 2 (Finnish sample) and 3 (Indian sample) containing descriptive statistics for the key constructs of the study, as well as the correlations between them, is helpful.

'Insert Tables 2 and 3 here'

\section{Test of Hypothesis 1: Predominance of dejection vs. agitation}

In order to test whether, in an unsuccessful intercultural business negotiation, negotiators from individualistic cultures would predominantly experience dejectionrelated emotions and negotiators from collectivistic cultures agitation-related emotions, paired sample t-tests were conducted for the Finnish and Indian samples.

The results of these tests indicate that the dejection-related emotions $(\mathrm{M}=1.69$, $\mathrm{SD}=0.80)$ predominated over the agitation-related emotions $(\mathrm{M}=1.06, \mathrm{SD}=0.61)$ amongst the Finns $(t(105)=10.91, p<0.01)$ and that for the Indians $(t(113)=5.46, p<$ $0.01)$ the same directionality held $\left(\mathrm{M}_{\text {dejection }}=1.33, \mathrm{SD}_{\text {dejection }}=0.69 ; \mathrm{M}_{\text {agitation }}=1.04\right.$, $\left.\mathrm{SD}_{\text {agitation }}=0.57\right)$. Thus, in line with $\mathrm{Hla}$, the more individualistic Finns experienced more dejection-related than agitation-related emotions. The more collectivistic Indians, however, did not experience greater agitation than dejection, as originally predicted (H1b was not supported). The correlations between individualism/collectivism and dejection/agitation (see Tables 2 and 3) also resonate with these findings. In the Finnish sample, namely, individualism is positively correlated with dejection $(\mathrm{r}=0.21, \mathrm{p}<$ 
$0.05)$ and is not linked to agitation $(\mathrm{r}=0.09, \mathrm{p}>0.05)$. By contrast, in the Indian sample, collectivism is negatively correlated with dejection $(\mathrm{r}=-0.28, \mathrm{p}<0.01)$ which is consistent with H1b. However, contrary to it, collectivism is negatively related to agitation $(r=-0.23, p<0.05)$ as well. In sum, these results render partial support for H1.

\section{Test of Hypothesis 2: Emotional volatility}

We now proceed to test whether, in an unsuccessful intercultural business negotiation, negotiators from collectivistic cultures demonstrate lower emotional volatility relative to their individualistic counterparts. Statistical analysis (another set of t-tests) revealed that Indians identified with both of the roles better than their Finnish counterparts and this difference was statistically significant for both roles. Indians identified more with the role of David than the Finns $\left(\mathrm{M}_{\text {David, IND }}=2.37\right.$ vs. $\mathrm{M}_{\text {David, FIN }}=1.79, \mathrm{SD}_{\text {David, IND }}=$ 0.90 vs. $\left.\mathrm{SD}_{\text {David, FIN }}=0.89, \mathrm{t}(105)=3.35, \mathrm{p}<0.001\right)$, and they also identified more with the role of Ishikawa than the Finns $\left(\mathrm{M}_{\text {Ishikawa, IND }}=2.18\right.$ vs. $\mathrm{M}_{\text {Ishikawa, FIN }}=1.55$, $\mathrm{SD}_{\text {Ishikawa, IND }}=0.84$ vs. $\left.\mathrm{SD}_{\text {Ishikawa, FIN }}=0.81, \mathrm{t}(104)=3.94, \mathrm{p}<0.001\right)$. This is consistent with the view that collectivists are better at perspective-taking. A better perspectivetaking ability goes hand in hand with higher cognitive capacity to consider the world from another individual's viewpoint and appreciate his/her interests, preferences, values and needs. This, in turn, should lead to lower emotional volatility.

The emotional volatility can be best assessed by comparing the differences in the specific emotional responding expressed by the Finns and Indians in the roles of David and Ishikawa. Table 4 describes the differences in the emotional responses between the Indians and the Finns as a function of the role that they played. The results suggest that the Finns experience the emotions differently in the roles of David vs. 
Ishikawa in 24 out of 30 cases. The Indians, by contrast, experienced emotions differently only in 8 out of 30 cases.

'Insert Table 4 here'

Table 4 also reports these results at the scale-level (see the capital-lettered lines). Even though this approach to some extent levels out the differences found at the itemlevel, the basic message remains the same. Across all of the five emotion classes, the role played (David vs. Ishikawa) made a strong difference in the experience of the Finns. In the case of the Indians, this only occurred across three emotion classes and with lower confidence levels.

The fact that the Finns experienced different sets of emotions depending upon whether they were playing David or Ishikawa suggests that they were insufficiently able to consider the world from the viewpoint of the other party and appreciate their interests, preferences, values and needs. Had such capacity been present, there would not have been such a difference in their emotional responding because of the moderating effect of perspective-taking ability. This is precisely what happened to more collectivistic Indians due to their greater ability to perspective-taking: the lower emotional volatility was its manifestation. Thus, empirical support was found for H2.

\section{Test of Hypothesis 3: Approach tendency}

As to test the last hypothesis, potential cultural antecedents and emotional facilitators behind the approach tendency in an unsuccessful intercultural business negotiation was assessed. Hierarchical regression analysis was conducted in order to uncover reasons for this behavioural tendency. 
The results of the first step of the hierarchical analysis suggest that neither individualistic mind set of the negotiator nor agitation-related or dejection-related emotions themselves affect approach tendency. Collectivistic mind set, on the contrary, positively affects approach tendency $(\mathrm{B}=0.17, \mathrm{p}<0.05)$. This direct effect is in line with the idea that collectivistic cultural values embrace harmony orientation and prevention goals (Kim and Nam 1998). In a collectivistic culture, relationships are highly valued and when they are brought into question then the collectivists will put in the effort to try to repair this breach. This tendency to avoid failure in harmony maintenance (prevention goal) drives them towards an approach tendency. Gender was used as a control variable in the analysis, since it is possible that women are more relationship-oriented and prevention-goal-directed than men (see e.g. Eagly 2009; Gervais et al. 2010; Greenhalgh and Gilkey 1993). However, the results reveal only a marginally significant effect that actually points to the opposite direction; women are less likely than men to approach the opposing side of negotiation after unsuccessful negotiations.

To further study potential moderating effects between negotiator's mind set and emotions, we first formed the standardized composites for each of these (four) variables and then multiplied the corresponding scores to create the relevant interaction terms (Mathieu et al. 1992). In partial support of H3a, it is found that the interaction between individualism and dejection-related emotions is positively $(\mathrm{B}=0.17, \mathrm{p}<0.05)$ related to approach tendency. In other words, a negotiator's individualistic mind set fosters approach tendency the more the negotiator experiences dejection-related emotions. This is an interesting finding, since neither high individualism nor strong dejection-related emotions individually has a significant effect on approach tendency; both of these conditions need to be satisfied. H3b, instead, does not receive support as the interaction 
effect between collectivism and agitation-related emotions on approach tendency is non-significant. The key results of the hierarchical regression analysis are presented in Table 5.

\section{'Insert Table 5 here'}

Identical hierarchical regression analysis was conducted for avoidance tendency, but the results were non-significant throughout. Interestingly, in the Finnish data, dejection is positively correlated $(\mathrm{r}=0.23, \mathrm{p}<0.05)$ with approach, while there is no such correlation in the Indian data (see Tables 2 and 3). In turn, it is agitation that is positively correlated with approach $(\mathrm{r}=0.21, \mathrm{p}<0.05)$ in the Indian data. This is not true for the Finnish data that, in contrast, show a positive correlation between agitation and avoidance $(\mathrm{r}=0.21,<0.05)$. While these correlations possess less analytical value, they are consistent with the general idea behind H3: the same emotions can lead to opposite behavioural tendencies in different cultures.

\section{Discussion}

In summary, this study finds partial support for the Hypotheses 1 and 3 and stronger support for the Hypothesis 2. The theoretical implications along with future research directions and limitations of the study are now discussed.

\section{Theoretical implications}

The present research carries theoretical implications for the study of intercultural negotiations. Scholars have noted that intercultural negotiations can often create interactional difficulties, yet with a few exceptions have failed to specify what factors are involved in these dynamics (for exceptions see George et al. 1998; Lee et al. 2006). While cultural determinants have been shown to have a pivotal role in intercultural dispute resolution, negotiators' personal situation-specific mental models can also be 
influential (Tinsley et al. 2011). This study highlights the importance of emotions in an intercultural negotiating context.

First of all, our evidence indicates that Finns experience negative emotions of all types (dejection and agitation) in an unsuccessful intercultural business negotiation to a greater degree than Indians. Furthermore, as predicted, Finns experience more of dejection- than agitation-related emotions and when dejected, engage in obtaining a more favourable outcome. To our knowledge this is the first empirical demonstration that links dejection-related emotions and individualism to an approach tendency. This finding is broadly illustrative of how negotiators from individualistic cultures deal with a lack of success in their negotiating efforts. An attempt to reengage with the other actor to achieve a more positive outcome is natural, given that individualistic negotiators are predominantly driven by the achievement goals as opposed to prevention-related goals. However, if the individualists' approach tendency is enacted in an overtly aggressive way, it may backfire (Kumar, 2004). This is not a proposition that has been explicitly tested here but it is a potential implication of the study that invites further consideration.

Indians, by contrast, seem to rarely experience negative emotions of any type (dejection or agitation) and instead report positive or neutral emotions such as happy, calm, satisfied, and regretful, even in the case of an unsuccessful negotiation. We propose that this is due to the greater perspective-taking ability of the collectivists as compared to their individualistic counterparts. Individuals who have a greater perspective-taking ability are more likely to overcome the emotionality associated with their responses (Galinsky et al. 2008), pointing to the need to incorporate it into moderation/mediation analyses to more fully and specifically understand its role (cf. Grant and Berry 2011). The empirical findings are quite clear on this inasmuch as the Indians demonstrate much lower emotional volatility relative to their Finnish 
counterparts. Yet, another intriguing potential account lies in the differences between the personal negotiation-specific mental models (e.g. variable sum- vs. fixed pieassumptions) of Finns and Indians (cf. Tinsley et al. 2011). Further research should pay attention to these theoretical implications.

Although collectivists have a greater perspective-taking ability which explains lower emotional volatility, we should note that this may be reinforced by the fact that emotional regulation is often easier for individuals in collectivistic cultures (e.g. Butler et al. 2007; Luomala et al. 2004). Ravali et al. (2007), in a study of Hindu Gujarati children, noted that they were socialized at a very early age to control the expression of their negative emotions. As they note (2007, p. 93) "Gujarati children perceived others to be less accepting of anger and sadness than pain, and also reported controlling anger and sadness more than physical pain". In a similar vein, Kakar and Kakar (2007, p. 199) note "The Indian mind has a harder time expressing anger and guilt but is more comfortable than the individualistic psyche in dealing with feelings of sympathy and shame".

These issues clearly need to be tested in other studies. In any event, the tendency of Indians to negate the impact of negative emotions either through better perspectivetaking ability and/or better emotional self-regulation suggests that they may more skilfully manage the potential downside that is often inherent in the expression of negative emotions. This is an intriguing finding implying an inherent advantage for Indians in cross-cultural negotiations. Whether these findings are unique to India or whether they might generalize to other collectivistic cultures such as China or Japan is an open question. India has not been an easy country to characterize in terms of any cultural typology (Ronen and Shenkar 1985; Sinha and Kanungo 1997). 
Study limitations and future research suggestions

This study, like others, has its share of limitations. Firstly, measuring emotions is not easy and while most studies utilize self-report measures of emotions it remains an open question as to how well they capture the essence of emotional experience (Barry et al. 2004; Kumar 2004). Secondly, the negotiation scenario that was used may abstract away from some of the unique aspects of the Finnish and the Indian approaches to negotiations. It is therefore conceivable that this may limit the realism of the scenario to the participants and, in doing so, may constrain their emotional responses to the lower end of the scale. At the same time, however, this may also limit any self-serving biases and provide a more conservative test of the hypotheses.

Thirdly, study participants' level of prior knowledge on American and Japanese negotiation culture and practices were not measured. Thus, it was not possible to evaluate the role played by prior knowledge in affecting the results. It is important that future studies include more control variables so that alternative explanations can be more systematically ruled out. Finally, while this study has tapped into negotiator intentions, it has not measured negotiator's actual behaviour, and given that intentions and behaviour do not always converge, some caution in interpreting the results are necessary. Nevertheless, the present research raises questions that need to be addressed in more detail in subsequent studies.

Our study is among the first to bridge a void in exploring the linkages between culture and emotions in an intercultural negotiation setting. Many scholars have observed that work in this area is limited (Cropanzano et. al 2012). To the extent that the linkages between culture and emotion have been investigated, the dominant focus has been on anger and tension (Adam and Shirako 2013; Druckman and Olekalns 2008; Lee et. al 2006). Although anger and tension are important emotions, there is a need to 
broaden our understanding about the role of other dejection- and agitation-related emotions. The present study made one such attempt in that it demonstrated how the experience of different emotions (dejection vs. agitation) is culture-dependent and can be associated with different behaviours.

The work reported in this paper can be extended in a number of different ways. For example, a broader range of samples from both individualistic and collectivistic cultures is needed so that the generalizability of the findings can be assessed. Since negotiations also vary in their level of complexity, it would be valuable to explore the role of interaction between culture and the negotiating context in the emergence of emotions. This work has focused on the emotions that individuals experience in a negotiating context. Yet, emotions can also be suppressed and/or displayed strategically (Kopelman et al. 2006). It, thus, remains an open question if dejection- and agitationrelated emotions can be equally suppressed or used strategically only in particular cultural contexts or more generally. This is also an avenue that deserves further exploration. We hope that this inquiry provides further impetus for reinvigorating the study of culture and emotions in an intercultural negotiating context.

\section{References}

Adair WL, Brett JM (2005) The negotiation dance: Time, culture, and behavioral sequences in negotiation. Organ Sci 16(1):33-51.

Adair WA, Okumura T, Brett JM (2001) Negotiation behavior when cultures collide: The US and Japan. J Appl Psychol 86(3):371-385.

Adair WA, Taylor MC, Tinsley CH (2009) Starting out on the right foot: Negotiation schemas when cultures collide. Negotiation Confl Manag Res 2(2):138-163. 
Adam H, Shirako A (2013) Not all anger is created equal: The impact of the expresser's culture on the social effects of anger in negotiations. J Appl Psychol 98(5):785798.

Allred KG (1999) Anger and retaliation: Toward an understanding of impassioned conflict in organizations. In: Bies RJ, Lewicki RJ, Sheppard BH (ed) Research on negotiation in organizations. JAI Press, Greenwich, pp. 27-58.

Allred KG, Mallozzi JS, Matsui F, Raia CP (1997) The influence of anger and compassion on negotiation performance. Organ Behav Hum Decis Process 70(3):175-187.

Bagozzi RP, Gopinath M, Nyer PU (1999) The role of emotions in marketing. J Acad Mark Sci 27(2):184-206.

Barry B, Fulmer IS, Van Kleef GA (2004) I Laughed, I Cried, I Settled: The role of emotion in negotiation. In: Gelfand MJ, Brett JM (ed) The handbook of negotiation and culture. Stanford University Press, Stanford, pp. 71-94.

Barsade SG, Gibson D (2007) Why does affect matter in organizations? Acad Manag Perspect 21(1):36-59.

Berkowitz L (1989) Frustration- aggression hypothesis: Examination and reformulation. Psychol Bull 106(1):59-73.

Bond MH (1994) Into the heart of collectivism: A personal and scientific journey. In: Kim U, Triandis HC, Kagiticbasi C, Choi S, Yoon G (ed) Individualism and collectivism: Theory, method, and applications. Sage Publications, Thousand Oaks, pp. 66-76.

Bosmans A, Baumgartner H (2005) Goal-relevant emotional information: When extraneous affect leads to persuasion and when it does not. J Consum Res 32(3):424-434. 
Brett JM (2000) Culture and negotiation. Int J Psychol 35(2):97-104.

Brett JM, Okumura T (1998) Inter- and intracultural negotiations: US and Japanese negotiators. Acad Manag J 41(5):495-510.

Bulow AM, Kumar R (2011) Culture and Negotiation. Int Negotiation 16(3):345-359.

Butler EA, Lee TL, Gross JJ (2007) Emotion regulation and culture: Are the social consequences of emotion suppression culture-specific? Emotion 7(1):30-48.

Brewer MB, Chen YR (2007) Where (who) are collectives in collectivism? Toward conceptual clarification of individualism and collectivism. Psychol Rev 114(1):133-151.

Chen CC, Chen XP, Meindl JR (1998) How can cooperation be fostered? The cultural effects of individualism-collectivism. Acad Manag Rev 23(2):285-304.

Cropanzano R, Becker WJ, Feldman J (2012) The effect of moods and discrete emotions on negotiator behavior. In: Goldman BM, Shapiro DL (ed) The psychology of negotiations in the $21^{\text {st }}$ century workplace (a volume in the SIOP organizational frontier series). Routledge, New York, pp. 141-179.

Davis MH (1983). Measuring individual differences in empathy: Evidence for the multidimensional approach. J Pers Soc Psychol 44(1):113-126.

De Mooij M (2004) Consumer behavior and culture. Consequences for global marketing and advertising. Sage Publications, Thousand Oaks.

Druckman D, Olekalns M (2008) Emotions in negotiation. Group Decis Negotiation 17(1):1-11.

Duronto PM, Nishida T, Nakayama S (2005) Uncertainty, anxiety, and avoidance in communication with strangers. Int J Intercult Rel 29(5):549-560.

Eagly AH (2009) The his and hers of prosocial behavior: An examination of the social psychology and gender. Am Psychol 64(8):644-658. 
Earley PC (1997) Face, Harmony, and Social structure: An analysis of Organizational Behavior across Cultures. Oxford University Press, New York.

Ekman P (1992) Are there basic emotions? Psychol Rev 99(3):550-553.

Everitt BS (2002) Cambridge Dictionary of Statistics. Cambridge University Press, New York.

Fiske ST, Taylor SE (1991) Social cognition. McGraw Hill, New York.

Frijda NH (1986) The emotions. Cambridge University Press, New York.

Galinsky AD, Maddux WW, Gillin D, White JB (2008) Why it pays to get inside the head of your opponent: The differential effects of perspective taking and empathy in negotiations. Psychol Sci 19(4):378-384.

Gelfand MJ, Brett J, Gunia BC, Imai L, Huang TJ, Hsu BF (2013) Toward a culture-bycontext perspective on negotiation: Negotiating teams in the United States and Taiwan. J Appl Psychol 98(3):504-513.

George JM, Jones GR, Gonzales JA (1998) The role of affect in cross-cultural negotiations. J Int Bus Stud 29(4):749-772.

Gervais SJ, Hillard AL, Vescio TK (2010). Confronting sexism: The role of relationship orientation and gender. Sex Roles 63(7-8):463-474.

Gibson DE, Callister RR (2010) Anger in organizations: A review and integration. J Manag 26(1):66-93.

Gilin D, Maddux WW, Carpenter J, Galinsky AD (2013) When to use your head and when to use your heart: The differential value of perspective-taking versus empathy in competitive interaction. Pers Soc Psychol Bull 39(1):3-16.

Goncalo JA, Staw BM (2006) Individualism-collectivism and group creativity. Organ Behav Hum Decis Process 100(1):96-109. 
Grant AM, Berry JW (2011) The necessity of others is the mother of invention: Intrinsic and prosocial motivations, perspective taking, and creativity. Acad Manag J 54(1):73-96.

Greenhalgh L. Gilkey RW (1993). The effect of relationship orientation on negotiators' cognitions and tactics. Group Decis Negotiation 2(2):167-186.

Gudykunst WB (1988) Uncertainty and anxiety. In: Kim YY, Gudykunst WB (ed) Theories in intercultural communication. Sage Publications, Newbury Park, pp. 123-156.

Gudykunst WB (2005) An anxiety/uncertainty management (AUM) theory of effective communication: making the mesh of the net finer. In Gudykunst WB (ed) Theorizing about intercultural communication. Sage Publications, Thousand Oaks, pp. 419-457.

Gunia BC, Brett JM, Nandkeolyar AK, Kamdar D (2011) Paying a price: Culture, trust, and negotiation consequences. J Appl Psychol 96(4):774-789.

Gupta RK, Panda A (2003) Individualised familial self: The evolving self of qualified technocrats in India. Psychol Dev Soc 15(1):1-29.

Higgins ET (1987) Self-discrepancy: A theory relating self and affect. Psychol Rev 94(3):319-340.

Hofstede G (2001) Culture's consequences: Comparing values, behaviors, institutions, and organizations across nations. Sage Publications, London.

Hofstede G, Jonker C, Verwaart T (2012) Cultural differentiation of negotiation agents Group Decis Negotiation 21(1):79-98.

Hughes R, Huby M (2002) The application of vignettes in social and nursing research. J Advanced Nurs 37(4):382-386. 
Hullett CR, Witte KM (2001). Predicting intercultural adaptation and isolation using the extended parallel process model to test anxiety/uncertainty management theory. J Int Intercult Rel 25(2):125-139.

Jones GR, George JM (1998) The experience and evolution of trust: Implications for co-operation and teamwork. Acad Manag Rev 23(3):531-546.

Kakar S, Kakar K. (2007) The Indians: Portrait of a people. Penguin Press, New Delhi.

Kim JY, Nam SH (1998) The concept and dynamics of face: Implications for organizational behavior in Asia. Organ Sci 9(4):522-534.

Kim MS, Raja NS (2003) When validity testing lacks validity: Comment on Levine et al. Hum Commun Res 29(2):275-290.

Kitayama S, Mesquita B, Karasawa M (2006) Cultural affordances and emotional experience: Socially engaging and disengaging emotions in Japan and the United States. J Pers Soc Psychol 91(5):890-903.

Kopelman S, Rosette AS (2008) Cultural variation in response to strategic emotions in negotiations. Group Decis Negotiation 17(1):65-77.

Kopelman S, Rosette AS, Thompson L (2006) The three faces of Eve: Strategic displays of positive, negative, and neutral emotions in negotiations. Organ Behav Hum Decis Process 99(1):81-101.

Kumar R (1997) The role of affect in negotiations: An integrative overview. J Appl Beh Sci 33(1):84-100.

Kumar R (1999a) A script-theoretical analysis of international negotiating behavior. In: Bies RJ, Lewicki RJ, Sheppard BH (ed) Research on negotiation in organizations. JAI Press, Greenwich, pp. 285-311.

Kumar R (1999b) Communicative conflict in intercultural negotiations: The case of American and Japanese business negotiations. Int Negotiation J 4(1):63-78. 
Kumar R (2004) Culture and emotions in negotiations. In: Gelfand MJ, Brett JM (ed) The handbook of negotiation and culture. Stanford University Press, Stanford, pp. 95-109.

Kunda Z (1990) The case for motivated reasoning. Psychol Bull 108(3):480-498.

Lazarus RS (1991) Emotion and adaptation. Oxford University Press, New York.

Lee KH, Yang G, Graham JL (2006) Tension and trust in international business negotiations: American executives negotiating with Chinese executives. J Int Bus Stud 37(5):623-641.

Leung K, Bond MH (1984) The impact of cultural collectivism on reward allocation. J Pers Soc Psychol 47(4):793-804.

Levine TR, Bresnahan MJ, Park HS, Lapinski MK, Wittenbaum GM, Shearman SM, Lee SY, Chung D, Ohashi R (2003) Self-construal scales lack validity. Hum Commun Res 29(2):210-252.

Li F, Aksoy L (2007) Dimensionality of individualism-collectivism and measurement equivalence of Triandis and Gelfand's scale. J Bus Psychol 21(3):313-328.

Liu LA, Friedman R, Barry B, Gelfand MJ, Zhang ZX (2012) The dynamics of consensus building in intracultural and intercultural negotiations. Adm Sci Q 57(2):269-304.

Luomala HT, Kumar R, Worm V, Singh D (2004) Cross-cultural differences in moodregulation: A comparison of individualistic and collectivistic cultures. J Int Consum Mark 16(4):39-62.

Mandler G (1975) Mind and emotion. John Wiley, New York.

Markus HR, Kitayama S (1991) Culture and the self: Implications for cognition, emotion, and motivation. Psychol Rev 98(2):224-253. 
Mathieu JE, Tannenbaum SI, Salas E (1992) Influences of individual and situational characteristics on measures of training effectiveness. Acad Manag J 35(4):828847.

McCullough ME, Worthington EL, Rachal KC (1997) Interpersonal forgiving in close relationships. J Pers Soc Psychol 73(2):321-336.

Mehrabian, A Russell, JA (1974) An approach to environmental psychology. MIT Press, Cambridge.

Mendes WB, Blascovich J, Hunter SB, Lickel B, Jost JT (2007) Threatened by the unexpected: Physiological responses during social interactions with expectancyviolating partners. J Pers Soc Psychol 92(4):698-716.

Moss S, Prosser H, Costello H, Simpson N, Patel P, Rowe S, Turner S, Hatton C (1998) Reliability and validity of the PAS-ADD. Checklist for detecting psychiatric disorders in adults with intellectual disability. J Intellect Disability Res 42(2):173-183.

Nickerson RS (1998) Confirmation bias: A ibiquitous phenomenon in many guises. Rev Gen Psychol 2(2):175-220.

Nunnally JC (1978) Psychometric Theory, 2nd edition. McGraw-Hill Book Company, New York.

Oetzel JG, Ting-Toomey S (2003) Face concerns in interpersonal conflict: A crosscultural empirical test of the face negotiation theory. Commun Res 30(6):599624.

Parker SK, Axtell CM (2001) Seeing another viewpoint: Antecedents and outcomes of employee perspective-taking. Acad Manag J 44(6):1085-1100.

Pruitt D, Rubin J, Kim SH (2003) Social conflict: Escalation, stalemate and settlement. McGraw Hill, New York. 
Ravali VV, Martini TS, Ravali H (2007) 'Would others think it is Okay to express my feelings?' Regulation of anger, sadness, and physical pain in Gujarati children in India. Soc Dev 16(1):79-105.

Ready KJ, Tessema MT (2009) Perceptions and strategies in the negotiation process: A cross cultural examination of U.S. and Malaysia. Int Negotiation 14(3): 493-517.

Roberts C, Lee WL, Chan KY (2006) An empirical analysis of measurement equivalence with the INDCOL measure of individualism and collectivism: Implications for valid cross-cultural inference. Pers Psychol 59(1):65-99.

Ronen S, Shenkar O (1985) Clustering countries on attitudinal dimensions: A review and synthesis. Acad Manag Rev 10(3):435-454.

Samochowiec J, Florack A (2010) Intercultural contact under uncertainty: The impact of predictability and anxiety on the willingness to interact with a member from an unknown cultural group. Int J Intercult Rel 34(5):507-515.

Schank RC, Abelson RP (1977). Scripts, plans, goals and understanding. An inquiry into human knowledge structures. Lawrence Erlbaum, Hillsdale.

Seo MG, Barrett LF, Bartunek JM (2004) The role of affective experience in work motivation. Acad Manag Rev 29(3):423-439.

Shaver P, Schwartz J, Kirson D, O’Connor G (1987) Emotion knowledge: Further exploration of a prototype approach. J Pers Soc Psychol 52(6):1061-1086.

Shweder R, Bourne J (1984) Does the concept of the person vary cross culturally? In: Shweder R, Levine R (ed) Culture Theory. Cambridge University Press, New York, pp. 158-189.

Singelis TM, Triandis HC, Bhawuk DS, Gelfand MJ (1995) Horizontal and vertical dimensions of individualism and collectivism: A theoretical and measurement refinement. Cross Cult Res 29(3):241-275. 
Sinha JBP, Kanungo RN (1997) Context sensitivity and balancing in Indian organizational behavior. Int J Psychol 32(2):93-105.

Ting-Toomey S, Kurogi A (1998) Facework competence in intercultural conflict: An updated face negotiation theory. Int J Intercult Rel 22(2):187-225.

Ting-Toomey S, Yee-Jung KK, Shapiro RB, Garcia W, Wright TJ, Oetzel JG (2000) Ethnic/cultural identity salience and conflict styles in four US ethnic groups. Int J Intercult Rel 24(1):47-81.

Tinsley CH, Turan N, Aslani S, Weingart LR (2011) The interplay between culturallyand situationally-based mental models of intercultural dispute resolution: West meets Middle East 1. Int Negotiation 16(3): 481-510.

Triandis HC, Gelfand MJ (1998) Converging measures of horizontal and vertical individualism and collectivism. J Pers Soc Psychol 74(1):118-128.

Ulijn JM, Rutkowski A, Kumar R, Zhu Y (2005) Patterns of feelings in face to face negotiations: A Sino-Dutch pilot study. Cross Cult Manag 12(3):103-118.

Usunier JC (2003) Cultural aspects of international business negotiations. In: Ghauri PN, Usunier JC (ed) International business negotiations. Pergamon Press, Amsterdam, pp. 97-135.

Van Kleef GA, de Dreu CW, Manstead AS (2004) The interpersonal effects of anger and happiness in negotiations. J Pers Soc Psychol 86(1):57-76.

Van Kleef GA, De Dreu CW, Pietroni D, Manstead AS (2006) Poer and emotion in negotiation: Power moderates the interpersonal effects of anger and happiness on concession making. Eur J Soc Psychol 36(4):557-581.

Watson D, Clark LA (1984) Negative affectivity: The disposition to experience negative emotional states. Psychol Bull 96(3):465-490. 
Wilks T (2004) The use of vignettes in qualitative research into social work values. Qual Soc Work 3(1):78-87.

Williams M (2007) Building genuine trust through interpersonal emotion management: A threat regulation model of trust and collaboration across boundaries. Acad Manag Rev 32(2):595-621.

Wu S, Keysar B (2007) The effect of culture on perspective taking. Psychol Sci 18(7): 600-606.

Yzerbyt V, Dumont M, Wigboldus D, Gordijn E (2003) I feel for us: The impact of categorization and identification on emotions and action tendencies. Br J Soc Psychol 42(4):533-549. 
Table 1. Emotions measured in the study.

\begin{tabular}{|c|c|}
\hline Emotion classes & Emotion items \\
\hline Positive (7) & calm, driven, friendly, happy, quiet, relaxed, satisfied \\
\hline Neutral (1) & neutral \\
\hline $\begin{array}{c}\text { Dejection-related } \\
(8)\end{array}$ & angry at other, disappointed, dissatisfied, frustrated, hopeless, \\
irritated, regretful, sad
\end{tabular}

Note. * This item was eliminated, based on the scale refinement procedure described below. 
Table 2. Means, standard deviations and correlations between the key constructs in the Finnish sample $(\mathrm{n}=106)$.

\begin{tabular}{lcccccccc}
\hline & Mean & S.D. & 1 & 2 & 3 & 4 & 5 & 6 \\
& & & & & & & & \\
\hline 1) Individualism & 5.58 & 1.07 & 1.00 & & & & & \\
2) Collectivism & 5.45 & 0.98 & 0.19 & 1.00 & & & & \\
3) Dejection & 1.69 & 0.80 & $0.21^{*}$ & 0.11 & 1.00 & & & \\
4) Agitation & 1.06 & 0.61 & 0.09 & 0.08 & $0.67^{* *}$ & 1.00 & & \\
5) Approach & 1.31 & 1.35 & 0.15 & 0.19 & $0.23^{*}$ & 0.07 & 1.00 & \\
6) Avoidance & 1.42 & 1.02 & $-0.20^{*}$ & $-0.20^{*}$ & 0.07 & $0.21^{*}$ & $-0.40^{* *}$ & 1.00 \\
\hline Note. ${ }^{*} p<0.05 . * * p<0.01$. & & & & & & & & \\
\hline
\end{tabular}


Table 3. Means, standard deviations and correlations between the key constructs in the Indian sample $(\mathrm{n}=114)$.

\begin{tabular}{|c|c|c|c|c|c|c|c|c|}
\hline & Mean & S.D. & 1 & 2 & 3 & 4 & 5 & 6 \\
\hline 1) Individualism & 6.57 & 0.88 & 1.00 & & & & & \\
\hline 2) Collectivism & 6.99 & 0.88 & $0.19 *$ & 1.00 & & & & \\
\hline 3) Dejection & 1.33 & 0.69 & -0.10 & $-0.28 * *$ & 1.00 & & & \\
\hline 4) Agitation & 1.04 & 0.57 & 0.08 & $-0.23 *$ & $0.63 * *$ & 1.00 & & \\
\hline 5) Approach & 1.82 & 1.08 & 0.17 & 0.04 & -0.01 & $0.21 *$ & 1.00 & \\
\hline 6) Avoidance & 1.46 & 1.16 & 0.00 & 0.03 & 0.12 & 0.03 & 0.00 & 1.00 \\
\hline
\end{tabular}


Table 4. Analyzing emotional volatility between the Finns and Indians as a function of the assigned role.

\begin{tabular}{|c|c|c|}
\hline & $\begin{array}{l}\text { Effect of role (David vs. Ishikawa) on } \\
\text { emotional responding in the Finnish data }\end{array}$ & $\begin{array}{l}\text { Effect of role (David vs. Ishikawa) on } \\
\text { emotional responding in the Indian data }\end{array}$ \\
\hline 1) POSITIVE & T-VALUE $=-4.02, \mathrm{p}<0.001$ & T-VALUE $=-2.50, \mathrm{p}<0.05$ \\
\hline EMOTIONS & & \\
\hline calm & 1) $\mathrm{T}$-value $=-4.28, \mathrm{p}<0.001$ & 1) $\mathrm{T}$-value $=-2.66, p<0.01$ \\
\hline driven & 2) $\mathrm{T}$-value $=4.96, \mathrm{p}<0.001$ & $\mathrm{~T}$-value $=0.56, \mathrm{p}>0.05$ \\
\hline friendly & 3) T-value $=-4.29, p<0.001$ & T-value $=-1.06, p>0.05$ \\
\hline happy & $\mathrm{T}$-value $=-1.75, \mathrm{p}>0.05$ & $\mathrm{~T}$-value $=-0.93, \mathrm{p}>0.05$ \\
\hline quiet & 4) $\mathrm{T}$-value $=-6.35, \mathrm{p}<0.001$ & $\mathrm{~T}$-value $=-1.72, \mathrm{p}>0.05$ \\
\hline relaxed & 5) $\mathrm{T}$-value $=-2.81, \mathrm{p}<0.01$ & 2) $\mathrm{T}$-value $=-2.67, p<0.01$ \\
\hline satisfied & 6) $\mathrm{T}$-value $=-2.82, \mathrm{p}<0.01$ & $\mathrm{~T}$-value $=-1.30, \mathrm{p}>0.05$ \\
\hline \multicolumn{3}{|l|}{ 2) NEUTRAL } \\
\hline EMOTIONS & & \\
\hline Neutral & 7) $\mathrm{T}$-value $=-4.71, \mathrm{p}<0.001$ & $\mathrm{~T}$-value $=-1.86, \mathrm{p}>0.05$ \\
\hline \multicolumn{3}{|l|}{ 3) } \\
\hline DEJECTION & T-VALUE $=6.03, p<0.001$ & $\mathrm{~T}-\mathrm{VALUE}=2.34, \mathrm{p}<0.05$ \\
\hline EMOTIONS & & \\
\hline angry at other & 8) $\mathrm{T}$-value $=5.02, \mathrm{p}<0.001$ & 3) $\mathrm{T}$-value $=3.59, \mathrm{p}<0.001$ \\
\hline disappointed & 9) $\mathrm{T}$-value $=4.70, \mathrm{p}<0.001$ & $\mathrm{~T}$-value $=1.51, \mathrm{p}>0.05$ \\
\hline dissatisfied & 10) $\mathrm{T}$-value $=5.68, \mathrm{p}<0.001$ & $\mathrm{~T}$-value $=-0.14, \mathrm{p}>0.05$ \\
\hline frustrated & 11) T-value $=5.96, p<0.001$ & 4) $\mathrm{T}$-value $=2.79, \mathrm{p}<0.01$ \\
\hline hopeless & 12) $\mathrm{T}$-value $=3.15, \mathrm{p}<0.01$ & $\mathrm{~T}$-value $=-0.43, \mathrm{p}>0.05$ \\
\hline irritated & 13) T-value $=4.59, \mathrm{p}<0.001$ & 5) $\mathrm{T}$-value $=3.93, \mathrm{p}<0.001$ \\
\hline regretful & 14) $\mathrm{T}$-value $=2.39, \mathrm{p}<0.05$ & T-value $=0.60, p>0.05$ \\
\hline sad & $\mathrm{T}$-value $=1.25, \mathrm{p}>0.05$ & T-value $=0.00, p>0.05$ \\
\hline \multicolumn{3}{|l|}{ 4) } \\
\hline AGITATION & $\mathrm{T}-$ VALUE $=2.74, \mathrm{p}<0.01$ & $\mathrm{~T}-\mathrm{VALUE}=2.60, \mathrm{p}<0.05$ \\
\hline \multicolumn{3}{|l|}{ EMOTIONS } \\
\hline angry at self & 15) $\mathrm{T}$-value $=3.36, \mathrm{p}<0.001$ & 6) $\mathrm{T}$-value $=2.38, \mathrm{p}<0.05$ \\
\hline anxious & 16) $\mathrm{T}$-value $=2.77, \mathrm{p}<0.01$ & 7) $\mathrm{T}$-value $=3.70, \mathrm{p}<0.001$ \\
\hline apprehensive & 17) $\mathrm{T}$-value $=4.89, \mathrm{p}<0.001$ & T-value $=0.67, p>0.05$ \\
\hline ashamed & T-value $=-1.35, p>0.05$ & $\mathrm{~T}$-value $=-0.52, \mathrm{p}>0.05$ \\
\hline fearful & T-value $=-0.11, p>0.05$ & $\mathrm{~T}$-value $=-0.11, \mathrm{p}>0.05$ \\
\hline pressured & 18) $\mathrm{T}$-value $=-6.42, p<0.001$ & T-value $=-0.09, p>0.05$ \\
\hline self-blaming & $\mathrm{T}$-value $=0.13, \mathrm{p}>0.05$ & $\mathrm{~T}$-value $=0.59, \mathrm{p}>0.05$ \\
\hline tense & 19) $\mathrm{T}$-value $=4.76, \mathrm{p}<0.001$ & 8) T-value $=2.63, p<0.01$ \\
\hline \multicolumn{3}{|l|}{ 5) OTHER } \\
\hline NEGATIVE & $\mathrm{T}-\mathrm{VALUE}=2.76, \mathrm{p}<0.01$ & $\mathrm{~T}$-VALUE $=0.33, \mathrm{p}>0.5$ \\
\hline \multicolumn{3}{|l|}{ EMOTIONS } \\
\hline confused & 20) $\mathrm{T}$-value $=4.72, \mathrm{p}<0.001$ & $\mathrm{~T}$-value $=0.78, \mathrm{p}>0.05$ \\
\hline indecisive & 21) $\mathrm{T}$-value $=-2.33, \mathrm{p}<0.05$ & $\mathrm{~T}$-value $=-1.44, \mathrm{p}>0.05$ \\
\hline resentful & 22) T-value $=6.28, \mathrm{p}<0.001$ & T-value $=0.91, p>0.05$ \\
\hline threatened & 23) T-value $=-2.50, p<0.05$ & $\mathrm{~T}$-value $=-1.87, \mathrm{p}>0.05$ \\
\hline uncertain & $\mathrm{T}$-value $=1.94, \mathrm{p}>0.05$ & T-value $=-0.59, p>0.05$ \\
\hline uneasy & 24) $\mathrm{T}$-value $=4.71, \mathrm{p}<0.001$ & T-value $=0.62, p>0.05$ \\
\hline
\end{tabular}

Note. Capital-lettered lines denote the scale-level results. 
Table 5. Results for the hierarchical regression analysis predicting approach tendency.

\begin{tabular}{lcc}
\hline Variable & Model 1 & Model 2 \\
\hline Constant & $0.02(0.03)$ & $-0.10(-0.13)$ \\
Individualism & $0.11(1.16)$ & $0.12(1.27)$ \\
Collectivism & $0.17^{* *}(2.21)$ & $0.18^{* *}(2.27)$ \\
Agitation & $0.07(0.34)$ & $0.11(0.53)$ \\
Dejection & $0.17(1.12)$ & $0.15(0.99)$ \\
Gender & $-0.38^{*}(-1.95)$ & $-0.38^{* *}(-2.05)$ \\
Collectivism x Agitation & & $0.01(0.23)$ \\
Individualism x Dejection & & $0.17^{* *}(1.97)$ \\
\hline \multicolumn{1}{c}{$\mathrm{R}^{2}$} & 0.10 & 0.12 \\
\hline
\end{tabular}

Note. Unstandardized coefficients are reported with $t$-values in parentheses

${ }^{*} p<0.10 ; * * p<0.05$ 
Appendix A. Key features of American culture as communicated by the vignette.

\begin{tabular}{|l|l|}
\hline $\begin{array}{l}\text { Individualistic aspects of American } \\
\text { culture }\end{array}$ & Illustrative excerpts from the vignette \\
\hline Low context communication & $\begin{array}{l}\text { 1) Dave: Well, what more do you want, folks? } \\
\text { 2) Dave: We would like to thank you for your generous } \\
\text { hospitality. } \\
\text { Kline: (adding): That Geisha place was great! }\end{array}$ \\
\hline Task orientation & $\begin{array}{l}\text { 1) On the second evening out on the town, the } \\
\text { Americans tried to bring the business issue to their } \\
\text { hosts' attention but were only met by smiling Japanese } \\
\text { faces who concomitantly placed an order for more } \\
\text { drinks. } \\
\text { 2) Kline: I can't see what those contracts have to do } \\
\text { with this? And besides, strictly speaking we have no } \\
\text { legal obligation to discuss the nature of those contracts } \\
\text { with you. }\end{array}$ \\
\hline Time sensitivity & $\begin{array}{l}\text { 1) Wright: We would like to point out that we cannot } \\
\text { wait indefinitely. As a matter of fact, we have recently } \\
\text { been approached by a Japanese firm which is interested } \\
\text { in the possibility of a joint venture in the United States. } \\
\text { 2) It had been four weeks since Norio had left, and } \\
\text { David had not heard anything about the matter. So } \\
\text { David called Norio in Tokyo, and found out that Norio } \\
\text { was abroad. After this David wrote to the Japanese } \\
\text { company and described his interest in their products } \\
\text { suggesting a meeting at their earliest convenience. }\end{array}$ \\
\hline Aggressive persuasion & $\begin{array}{l}\text { 1) Dave: Would it at all be possible for you to sign a } \\
\text { contract or come to some tentative agreement at this } \\
\text { point in time? } \\
\text { 2) Dave: That is right. We have been aiming at the } \\
\text { licence with exclusive rights in the North American } \\
\text { markets on condition that we would have the first call } \\
\text { on our possible future expansion into the European } \\
\text { market. }\end{array}$ \\
\hline Emphasis on achieving tangible \\
outcomes
\end{tabular}


Appendix B. Key features of Japanese culture as communicated by the vignette.

\begin{tabular}{|l|l|}
\hline $\begin{array}{l}\text { Collectivistic aspects of Japanese } \\
\text { culture }\end{array}$ & Illustrative excerpts from the vignette \\
\hline High context communication & $\begin{array}{l}\text { 1) He had barely uttered the question when he realized } \\
\text { that the Japanese were not responding. He noticed, in } \\
\text { fact, that one of them was taking a short snooze. } \\
\text { 2) Ishikawa: (crosses his arms on his chest, looks into } \\
\text { the ceiling and mutters) } \\
\text { Hmm....it...may...not...be so easy. We will write } \\
\text { to you as soon as possible. }\end{array}$ \\
\hline Relationship orientation & $\begin{array}{l}\text { 1) After having dined at one of Tokyo's exclusive } \\
\text { restaurants the Japanese took their guests to what was } \\
\text { probably one of the most popular geisha places in town. } \\
\text { 2) The following day was no different in that it also } \\
\text { included a long period of drinking and a visit to the } \\
\text { centre of nightlife. }\end{array}$ \\
\hline Patience & $\begin{array}{l}\text { 1) Ishikawa: Maybe we should discuss this at another } \\
\text { occasion? } \\
\text { 2) Ishikawa: We need more time to consider your } \\
\text { proposal. } \\
\text { Dave: Do you think one more meeting will be needed? } \\
\text { Ishikawa: Maybe so. }\end{array}$ \\
\hline $\begin{array}{l}\text { Minimizing uncertainty and } \\
\text { developing confidence in their } \\
\text { partner }\end{array}$ & $\begin{array}{l}\text { 1) Ishikawa: How much of an assistance do you } \\
\text { anticipate you might require from us in effectively } \\
\text { utilizing the technology? } \\
\text { 2) Ishikawa: We understand you are aiming at the } \\
\text { European markets right now. Do you have any plans } \\
\text { regarding Asia? We would like to familiarize ourselves } \\
\text { with your plans having to do with this proposal. }\end{array}$ \\
\hline $\begin{array}{l}\text { Emphasis on intangible outcomes } \\
\text { contact with the Americans. They then began speaking } \\
\text { quietly amongst each other in Japanese. } \\
\text { 2) Ishikawa: On behalf of Suzuki-san we wish you } \\
\text { welcome to our country. We hope your visit will be a } \\
\text { pleasant one. Your country, as we all know, is the } \\
\text { leading in the world... } \\
\text { (for 15-20 minutes he goes on to praise the United } \\
\text { States for its great achievements and good will.) }\end{array}$ \\
\hline
\end{tabular}

